\title{
Sistem Anti fraud berbasis Metafora "Ronda": Suatu usulan untuk Indonesia
}

\author{
Oleh: \\ Habib Muhammad Shahib ${ }^{1}$ \\ Mahasiswa Program Doktor Ilmu Akuntansi, Universitas Brawijaya, Malang
}

\begin{abstract}
Abstrak
Bangunan sistem anti fraud di seluruh dunia selama ini cenderung didominasi oleh model yang seragam dan berakar pada American-Western European style. Meski, terus ditemukan fakta, banyak sistem anti fraud tidak dapat berjalan efektif akibat tidak mempertimbangkan budaya lokal dalam pengaplikasiannya. Artikel ini kemudian mencoba meminjam paradigma posmodern dan metode metafora untuk mengkaji kumpulan teks di dunia maya guna menciptakan satu sistem anti fraud berbasis budaya ronda, demi menghadirkan sistem anti fraud yang sesuai bagi karekteristik bangsa Indonesia. Hasilnya, simpulan sementara artikel ini menemukan budaya ronda dapat menjadi metafora guna membangun sistem anti fraud khas Indonesia dan menyarankan untuk menghadirkan pengawalan penegakan hukum atas tindakan fraud sebagai salah satu bagian integral dari sistem anti fraud di Indonesia.
\end{abstract}

\section{Kata kunci : Sistem anti fraud, Metafora, Budaya Ronda, Indonesia}

\section{Pendahuluan}

Kajian tentang sistem pencegahan (preventive), deteksi dan pemberian efek jera (deterrence) atas kasus fraud selama ini cenderung didominasi oleh cara pandang yang seragam dengan berkiblat kepada American-Western European style (Haller dan Shore, 2005; Bierstaker, 2009; Whyte dan Wiegratz, 2016). Cara pandang tersebut menjuruskan fokusnya hanya kepada organisasi atau perusahaan tempat terjadinya fraud dan individu yang diduga terlibat, mulai dari bagaimana mencegah individu agar tidak melakukan fraud, bagaimana menginvestigasi individu yang terlibat fraud, dan bagaimana cara memberikan efek jera kepada pelaku fraud (Wolfe dan Hermanson, 2004; Bierstaker, 2009; Dorminey et al., 2012).

Di sisi lain, kajian atas pengawalan kasus fraud yang telah masuk dalam proses hukum, seperti kasus yang telah di proses oleh polisi, lembaga anti fraud, hingga pengadilan, masih belum menjadi konsen utama dan terintegrasi dalam kajian sistem anti fraud (Holtfreter et al., 2008). Sehingga efek jera dan kejut kepada lapisan masyarakat lainnya masih cenderung lemah. Hal ini dapat terlihat dari semakin canggihnya transformasi tindakan fraud meski begitu banyak kajian dan implementasi sistem anti fraud termutakhir hadir di seluruh dunia (ACFE, 2016). Hal yang mana juga terjadi di Indonesia, penindakan atas kasus fraud cenderung jauh dari memberi efek jera dan kejut kepada masyarakat, tercermin dari jumlah kasus fraud yang cenderung meningkat sepanjang tahun 2010 hingga 2017 (KPK, 2017). Ditambah lagi proses administrasi hukum di Indonesia atas kasus fraud, khususnya korupsi, sangat memakan waktu dengan berbagai alasan, seperti masih dilakukan pendalaman kasus oleh penyidik, saksi atau penyidik yang kurang (OKEZONE.COM, 2014), antri dengan kasus lain, serta akibat tidak memiliki dukungan politis yang kuat (Republika, 2017). Celah ini kemudian sering kali diintervensi oleh tindakan kolusi antara tersangka dan penegak hukum untuk meringankan atau menghindari hukuman (Indrayana, 2008).

Berdasarkan penjelasan tersebut, menjadi menarik kemudian untuk mengkaji kemungkinan hadirnya fungsi baru dalam sistem anti fraud di Indonesia, yakni fungsi pengawalan kasus fraud di ranah hukum, sebagai fungsi pelengkap dari tiga fungsi sistem

\footnotetext{
${ }^{1}$ Korespondensi: muh.shahib@gmail.com
} 
anti fraud lainnya (pencegahan, deteksi, dan deterrence), agar efek kejut dan jera di tengahtengah masyarakat terasa gaungnya dan dapat berujung pada menurunnya jumlah tindakan fraud. Artikel ini kemudian mencoba untuk melengkapi sistem anti fraud tersebut dengan menggunakan pendekatan metafora berbasis budaya "ronda" yang merupakan budaya (kebiasaan sosial) yang telah dilakukan berabad-abad oleh masyarakat nusantara [yang hari ini menjelma menjadi Indonesia] untuk menekan tingkat kejahatan di lingkungan pemukiman (Rafael, 1999; Mahadewi, 2014; Widodo, 2016; Maftuchin dan Budiyanto, 2017). Penggunaan kata "budaya" dalam frase "budaya ronda" dalam artikel ini berdasar pada pandangan Mulyana dan Rakhmat (1996) bahwa budaya meliputi banyak kegiatan dan kebiasaan sosial manusia yang terus menerus dilakukan berulang. Sehingga tepat rasanya jika ronda pun dianggap sebagai salah satu budaya Indonesia.

Lebih jauh, artikel ini menggunakan pendekatan metafora agar dapat memberikan efek "spesial" kepada pembaca yakni menghadirkan kedekatan psikologis, sosiologis dan budaya (Llewelyn, 2003; Mantere et al., 2007; Amernic dan Craig, 2009; Kusdewanti et al., 2014; Wahyuni, 2015) sehingga dapat mempermudah pembahasan dan pemahaman akan pentingnya kehadiran fungsi keempat dalam suatu sistem anti fraud di Indonesia. Hal tersebut juga berdasar pada saran peneliti fraud terdahulu, bahwa pengembangan suatu sistem anti fraud haruslah mempertimbangkan nilai budaya lokal di mana sistem tersebut akan diterapkan, agar tercipta keharmonisan antara sistem dan para pengguna sistem sehingga dapat berujung pada efektifnya penerapan sistem tersebut (Bierstaker, 2009; Bertot et al., 2010). Artikel ini kemudian ditulis secara sistematis sebagai berikut: bagian awalpendahuluan, kedua-metode, ketiga-hasil dan pembahasan, dan ditutup dengan kesimpulan sementara.

\section{METODE}

Penggunaan metode metafora dalam riset dan kajian ilmu sosial-ekonomi bukanlah hal yang aneh dan baru, khususnya riset yang mengambil paradigma posmodern sebagai acuan analisanya (Llewelyn, 2003; Mantere et al., 2007; Amernic dan Craig, 2009; Kusdewanti et al., 2014; Wahyuni, 2015). Kelebihan metode metafora sebagai alat analisa terletak pada kemampuannya untuk mempermudah pembaca untuk memahami penjelasan realitas dengan lebih sederhana dan dekat dengan dirinya secara sosiologis dan budaya (Kusdewanti et al., 2014; Wahyuni, 2015). Sebagai artikel yang mencoba mengembangkan dan melengkapi sistem anti fraud berbasis budaya ronda, artikel ini mencoba untuk memfokuskan pada penggunaan metafora berbasis telahaan "organ persepsi" sebagaimana yang dicontohkan oleh Amernic dan Craig (2009) dan Kusdewanti et al. (2014). Organ persepsi dalam konteks artikel ini adalah karakter atau nilai yang hadir dalam budaya "ronda" untuk menekan tindak kejahatan di tengah-tengah masyarakat Indonesia. Karakter atau nilai tersebut diperoleh dengan melakukan abstraksi dari berbagai jenis tulisan yang ditemukan di situs pencarian "google", mulai dari artikel ilmiah hingga berita online yang menjelaskan tentang "ronda".

Lebih lanjut, penggunaan berbagai jenis tulisan tersebut lebih kepada memudahkan untuk memetakan wacana dominan tentang budaya "ronda" di tengah-tengah masyarakat Indonesia. Hal ini juga selaras dengan pendapat Fairclough (2013) bahwa sebaran teks dapat menjadi alat pemetaan atas suatu wacana dominan di tengah-tengah masyarakat. Selanjutnya, dalam proses analisis, beberapa frase, kata, klausa, dan kalimat yang ditemukan dalam teks teks terkait "ronda" akan dikutip dan ditulis tebal guna mengidentifikasi bagian-bagian penting yang dianggap sebagai metafora sistem anti fraud sehingga dapat digunakan untuk menarik kata kunci dan nilai yang dapat dijadikan acuan untuk menyempurnakan sistem anti fraud di Indonesia. 


\section{HASIL DAN PEMBAHASAN}

Dengan menggunakan mesin pencari google, melalui laman "google scholar" ditemukan fakta terdapat kurang lebih 1.350 artikel yang membahas budaya ronda (GoogleScholar, 2017). Hasil berbeda ditemukan dengan menggunakan laman google utama, ditemukan 339.000 hasil pencarian dengan menggunakan kata kunci budaya ronda (Google, 2017). Hal ini seolah mengaminkan pendapat Fairclough (2013) bahwa sebaran teks dapat mengindikasikan hadirnya suatu wacana. Budaya ronda dalam hal ini dapat dikatakan sebagai salah satu wacana yang melekat dalam kehidupan sehari-hari masyarakat Indonesia sebab begitu banyak tulisan yang mengkaji dan merekam budaya ronda bertebaran di dunia maya.

Lebih lanjut, melalui penelusuran literatur digital terkait wacana budaya ronda yang muncul dalam daftar temuan google, ditemukan bahwa budaya ronda yang dalam KBBIDARING (2017) berarti "berjalan berkeliling untuk menjaga keamanan" telah hadir dan berakar di tengah-tengah masyarakat jauh sebelum kolonialisme hadir di Indonesia (Rafael, 1999; Historia.id, 2010). Hal tersebut tergambar dari salah satu perangkat ronda "kentongan" yang memiliki sejarah telah berabad-abad digunakan oleh peronda (individu yang melakukan ronda (KBBI-DARING, 2017)) dan masyarakat di nusantara (Nuryanto, 2012) sebagai alat komunikasi berbasis bunyi yang memiliki irama tertentu untuk menginformasikan masyarakat atas bahaya bencana alam dan kejahatan yang mengancam pemukiman masyarakat (Nuryanto, 2012).

Selanjutnya, dalam praktiknya, kelompok peronda seringkali berhasil mengamankan pelaku kejahatan yang beroperasi di lingkungan pemukiman masyarakat sebagaimana kutipan berita berikut:

"Seorang pencuri nyaris tewas dihakimi massa setelah kepergok mencuri di warung di Desa Pardasuka, Katibung, Lampung Selatan, pada Minggu (2/4/2017) sekitar pukul 01.30 WIB.Pelaku diketahui bernama Jaelani (28), warga Kelurahan Srengsem, Panjang. Ia dipergoki para peronda saat berusaha membuka papan penutup (bidak) warung milik Mursiti.....Beruntungnya aparat kepolisian dari Polsek Tanjungan segera datang ke lokasi dan langsung mengamankan pelaku dari amukan massa." (Lentera-Swara-Lampung, 2017)

"Aksi pencurian warga Glondongan, Mrangan, Polokarto, Wiyono (35) diketahui peronda di Dusun Purwoasri, Bangsri, Karangpandan. Pelaku yang kedapatan menjarah sekarung sarang burung walet nyaris dihakimi massa."(Krjogja.com, 2016)

Lebih lanjut, selain kemampuan ronda mengamankan lingkungan dari pelaku kejahatan biasa, seperti pencurian dan perampokan. Ronda juga dipercaya sebagai salah satu bantuan utama pihak kepolisian dalam mencegah dan mengungkap kasus kejahatan luar biasa dan terorisme. Sebagaimana yang digambarkan dalam potongan berita berikut:

"Ia [AKP Rita Suryanti-Kepala Bagian Humas Polres Bukittinggi] mengatakan karena keterbatasan petugas kepolisian, maka partisipasi masyarakat dalam menjaga keamanan melalui ronda akan sangat membantu tugas pihak keamanan."Sepanjang 2017 ini, kasus kriminal paling mencolok yaitu pencurian sepeda motor yang dapat dikatakan setiap hari terjadi di wilayah hukum Polres Bukittinggi, lalu satu kasus perampokan dengan kekerasan yang menyebabkan satu korban tewas yang baru-baru ini terjadi," kata dia. Ia berharap masyarakat turut menjadi polisi bagi diri sendiri melalui sikap peduli dan waspada serta aktif menjaga kamtibmas..." (OKEZONE.COM, 2017) 
"Anggota Polsek Dramaga menyebar poster-poster berisi foto para pelaku tindak pidana terorisme yang saat ini masuk dalam Daftar Pencarian Orang (DPO) Polri, Sabtu (30/1/2016). Poster bergambar foto sepuluh orang itu antara lain dipasang di Kantor Kepala Desa Dramaga, perumahan Dramaga Cantik dan pos ronda lingkungan warga Rt 1/1 Desa Dramaga, Kecamatan Dramaga, Kabupaten Bogor, Jawa Barat....Kepolisian berharap masyarakat yang mengetahui atau pernah melihat wajah orang yang berada di dalam poster tersebut agar segera melapor ke kantor polisi terdekat"(Tribunnewsbogor.com, 2016)

\section{“Organ persepsi” ronda: sistem penjaga keamanan}

Dari fenomena budaya ronda yang ditemukan dalam berita di atas, ditemukan beberapa metafora yang ditandai dengan huruf cetak tebal yang dapat dijadikan dasar pengembangan sistem anti fraud khas Indonesia. Mengapa demikian? Sebab bangunan budaya ronda memang telah menjadi suatu sistem sosial penjaga keamanan itu sendiri. Merujuk pada lengkapnya elemen-elemen sosial yang dimilikinya, khususnya terkait tindakan dan interaksi antar individu (Ritzer, 2010) dalam ronda itu sendiri sebagai suatu sistem penjaga keamanan lingkungan masyarakat, mulai dari adanya "peronda" sebagai metafora individu yang terlibat aktif dalam aktivitas ronda, "kentongan" sebagai metafora medium komunikasi, "dihakimi massa" sebagi metafora hukuman dan efek jera, dan "partisipasi masyarakat dalam menjaga keamanan melalui ronda" sebagai metafora bentuk pengawalan kasus kejahatan besar di tengah masyarakat. Selanjutnya, lima metafora inti tersebut kemudian akan dianalogikan dalam pengembangan sistem anti fraud khas Indonesia berikut ini.

\section{Metafora "ronda" sebagai sistem anti fraud yang "berbeda"}

Dalam kajian sistem anti fraud arus utama, dikenal tiga bagian utama sistem anti fraud yang dikenal dengan preventive (pencegahan), detection (deteksi), dan detterence (efek jera) (Bierstaker et al., 2006; Dorminey et al., 2012). Sayangnya, bebebapa akademisi menilai, terdapat kelamahan-kelemahan dalam sistem anti fraud arus utama tersebut seperti: ketiga bagian tersebut cenderung tidak terintegrasi sehingga hanya berfokus kepada tugas masing-masing bagian, fokus sistem tersebut cenderung berfokus kepada individu pelaku fraud hingga diserahkan ke pihak penegak hukum (Bierstaker, 2009; Dorminey et al., 2012) sedangkan pengawalan atas penegakan hukum kasus tersebut belum menjadi konsen utama, bangunan sistem anti fraud cenderung dibangun di atas pandangan hidup individualis dan neoliberal sehingga berujung pada hadirnya banyak badan pengawas namun disisi lain keinginan individu untuk terus memperkaya diri melalui tindakan fraud tetap tidak terkendali bahkan semakin canggih (Whyte dan Wiegratz, 2016), diperparah dengan diekspornya model ini ke negara-negara yang cenderung memiliki pandangan hidup berbeda, sehingga akhirnya berujung pada diterapkanny sistem anti fraud tersebut namun cenderung tidak dapat berjalan efektif sebab tidak selaras dengan nilai lokal (Bierstaker, 2009; Widodo, 2016).

Di sisi lain, ronda, sebagai suatu sistem penjaga keamanan masyarakat, memiliki perbedaan mencolok dengan sistem anti fraud arus utama meski sama-sama bertujuan untuk menghindari dan mengalahkan kejahatan (fraud). Hal itu disebabkan, ronda dibangun dalam kultur masyarakat indonesia yang komunal-kolektif (Rafael, 1999; Historia.id, 2010; Mahadewi, 2014; Widodo, 2016; Maftuchin dan Budiyanto, 2017). sehingga jauh dari semangat individualis dan liberal, hal ini dapat dilihat dari tidak adanya tindakan membedakan status sosial warga dalam penugasan sebagai peronda, seluruh warga di satu perkampungan atau pemukiman wajib mengikuti jadwal ronda yang telah disepakati bersama dengan konsekuensi (denda) yang sama jika tidak mengikutinya (Lestari et al., 2017). Jika 
hal ini ditarik sebagai analogi awal pembangunan sistem anti fraud maka kewajiban untuk mencegah dan mendeteksi tindakan fraud di suatu organisasi tidak lagi dibebankan hanya kepada organ atau individu tertentu yang memiliki kemampuan khusus seperti departeman internal audit, akuntan/auditor forensik, auditor eksternal, manajemen pengendalian dsb. Melainkan haruslah digilir secara merata di antara anggota organisasi sehingga dengan sendirinya akan tercipta pendidikan berbasis praktik dan hadir nilai anti fraud di tiap kelompok dan anggota organisasi.

\section{Metafora "peronda" sebagai pencegah dan penghukum tindakan fraud}

Selanjutnya, yang menarik dari metafora peronda, dalam sistem ronda, peronda dan kelompoknya adalah unsur utama pencegah sekaligus penghukum tindakan kejahatan yang terjadi di lingkungan masyarakat. Dimulai dari peronda akan aktif berkeliling dilingkungannya untuk mencegah kehadiran penjahat, kemudian apabila menemukan tindakan atau pelaku kejahatan, maka peronda akan dengan segera berusaha menangkap penjahat tersebut jika memungkinkan. Namun, jika peronda merasa tidak mampu untuk menyelesaikannya, maka kentongan akan dibunyikan bersama dengan teriakan “maling!!” sebagai tanda bahwa mereka membutuhkan warga lainnya untuk meringkus penjahat. Ketika penjahat tersebut berhasil ditangkap maka peronda ikut serta bersama warga untuk memberikan hukuman keras agar timbul efek jera bagi penjahat dan efek getar bagi calon penjahat lainnya. Sebagaimana yang digambarkan dalam kutipan berita berikut:

"Sekawanan pencuri gabah disergap warga Desa Kemiri dan Desa Tegalsari, Kepanjen, Kabupaten Malang, Senin diri hari (9/10). Tak ayal dua dari empat pelaku dihakimi hingga babak belur.....Kejahatan mereka dipergoki peronda, yang seketika berteriak maling..." (Klikapa.com, 2016)

Sehingga, jika metafora peronda tersebut dianalogikan ke dalam pembangunan sistem anti fraud. Maka seharusnya, individu atau kelompok individu yang ditugaskan dalam pos anti fraud di suatu organisasi adalah orang-orang yang aktif untuk bergerak melakukan pencegahan fraud di organisasinya dengan memanfaatkan sebaik-baiknya sarana komunikasi (baca: whistleblower system) untuk segera digunakan jika menemukan indikasi terjadinya fraud. Serta segera memberikan hukuman yang keras bagi pelanggarnya berdasarkan aturan yang berlaku.

\section{Metafora "kentongan"sebagai alat komunikasi sistem anti fraud}

Kentongan dapat dikatakan merupakan alat yang tidak terpisahkan dalam budaya ronda di Indonesia. Perannya sangat vital sebagai alat komunikasi yang digunakan peronda berbasis bunyi dengan kode-kode irama tertentu untuk memberitahukan suatu kejadian kepada masyarakat, khususnya jika mendapatkan informasi kejahatan atau bencana alam (Nuryanto, 2012). Fungsi kentongan sebagai alat komunikasi sudah sangat diwakili dengan kemajuan teknologi informasi dan komunikasi (TIK). Terlebih dalam pengembangan sistem anti fraud yang berbasis pada pengembangan whistleblower system yang canggih (Bertot et al., 2010; Hussien dan Yamanaka, 2017) sehingga mampu menekan dan melaporkan terjadinya fraud dengan efektif. Hanya saja, terdapat beberapa catatan tentang pengembangan komunikasi sistem anti fraud menurut Bertot et al. (2010) yaitu: (1) Pengembangan sistem komunikasi anti fraud sebaiknya berfokus kepada peningkatan literasi TIK bagi para anggota organisasi, sehingga anggota organisasi dapat dengan mudah menggunakan sistem tersebut untuk pencegahan dan pendeteksian fraud. (2) Pemerintah sebaiknya mendukung infrastruktur TIK hingga ke wilayah terpencil guna meningkatkan jangkauan pencegahan dan pendeteksian fraud. (3) Departemen terkait, seperti departemen audit internal dan penegak 
hukum, yang memiliki sistem anti fraud, khususnya whistleblower system sebaiknya membuat acuan standar terkait red flag dan tindakan follow up atas laporan kasus fraud sehingga pencegahan, pendeteksian, dan penegakan hukum terkait kasus fraud dapat dengan efektif terselesaikan.

\section{Metafora "dihakimi massa" sebagai pemberian efek jera bagi pelaku fraud}

Lebih lanjut, dalam hal menghadirkan hukuman yang keras atas tindakan fraud, "dihakimi massa" menjadi basis metaforanya. Tentu, tidak perlu keras secara fisik sebab saat ini ada hukum yang melindungi semua individu. Hukuman yang keras ini lebih tepatnya dihadirkan dalam bentuk: (1) Menghilangkan kemampuan pelaku fraud tersebut untuk melakukan fraud kembali, seperti langsung menyita kekayaan atau asetnya senilai 10 kali lipat dari dampak tindakan fraud-nya sekaligus (2) Memberhentikan atau memecatnya dengan tidak hormat dan (3) diumumkan di seluruh media massa dan media sosial kepada masyarakat sehingga masyarakat dapat langsung menghukumnya secara sosial. Namun, terdapat catatan yaitu hal tersebut tidak dapat langsung diterapkan tanpa adanya kebijakan atau kontrak yang mengatur hal tersebut dalam aturan organisasi terlebih dahulu. Sehingga aturan pemberian efek jera kepada para pelaku fraud dalam organisasi harus dirancang dengan baik terlebih dahulu sebelum diterapkan. Lebih jauh, metafora "dihakimi massa" juga dapat diartikan sebagai proses membangun kesadaran kolektif warga atau anggota organisasi yang terimbas oleh tindakan fraud agar terus mengawal penegakan hukum seberatberatnya kepada para pelaku fraud, yang belum menjadi kajian utama di sistem fraud arus utama (Wolfe dan Hermanson, 2004; Bierstaker et al., 2006; Dorminey et al., 2012)

\section{Metafora "partisipasi masyarakat dalam menjaga keamanan melalui ronda" sebagai bentuk pengawalan masyarakat atas penegakan hukum kepada pelaku fraud}

Salah satu poin penting dari kritik para akademisi atas sistem anti fraud arus utama, adalah tidak dijadikannya pengawalan penegakan hukum atas kasus fraud sebagai salah satu hal yang utama dalam sistem anti fraud (Holtfreter et al., 2008; Bertot et al., 2010; Whyte dan Wiegratz, 2016). Padahal, pengawalan penegakan hukum adalah hal yang sangat penting untuk memastikan pelaku fraud dihukum dengan berat agar dapat memutus tindakan fraud dan dapat memuaskan rasa keadilan masyarakat (Holtfreter et al., 2008). Beberapa hal yang kemudian dapat dipertimbangkan dari metafora "partisipasi masyarakat dalam menjaga keamanan melalui ronda" agar dapat menghadirkan fungsi pengawalan hukum kasus fraud dalam sistem anti fraud antara lain: (1) Dalam ronda, masyarakat yang berpartisipasi berasal dari berbagai jenis latar belakang (Lestari et al., 2017) namun dapat bersatu dalam satu tim ronda guna menghalau kejahatan dan menghukum penjahat di lingkungannya. Dari hal ini, dapat ditarik suatu garis besar, bahwa kejahatan, dalam hal ini fraud harus diasosiasikan dan disosialiasikan sebagai musuh penghancur atau kejahatan luar biasa atas tatanan masyarakat, sehingga masyarakat dapat memandangnya lebih hina dari kejahatan-kejahatan kecil lainnya dan akhirnya tertarik untuk memeranginya secara bersama-sama. (2) Sebagaimana peronda yang aktif memukul kentongan untuk mengajak partisipasi warga lain dalam menjaga keamanan, jadikan departeman humas (hubungan masyarakat) di tiap organisasi lebih aktif untuk menyebarluaskan informasi terkait proses hukum pelaku fraud yang berasal dari organisasinya sehingga akan hadir efek getar ke dalam dan luar organisasi sekaligus. (3) Juga harus turut aktif mengajak keterlibatan lembaga swadaya masyarakat (LSM) anti korupsi dan media elektronik lainnya dalam rangka mengawal penegakan hukum atas pelaku fraud sehingga meminimalkan peluang pelaku fraud untuk bermain mata dengan aparat penegak hukum. (4) Terakhir, organisasi haruslah menggandeng lawyer yang handal agar pelaku fraud dapat dituntut dengan hukuman maksimal, layaknya peronda menggandeng Polisi atau TNI sebagai mitra penjaga lingkungan. 


\section{KESIMPULAN SEMENTARA}

Ronda sebagai bagian budaya Indonesia dianggap tepat untuk menjadi basis metafora pengembangan sistem anti fraud alternatif untuk seluruh jenis organisasi di Indonesia. Berangkat dari fakta bahwa tiap wilayah memiliki kekhasan budayanya masing-masing yang seringkali tidak dipertimbangkan dalam membangun sistem anti fraud, sehingga sistem anti fraud cenderung tidak efektif dalam menekan hadirnya fraud (Haller dan Shore, 2005; Bierstaker, 2009). Lebih lanjut, penggunaan ronda sebagai basis metafora artikel ini, semakin menguatkan ide bahwa dibutuhkan bagian keempat yakni pengawalan penegakan hukum kepada pelaku fraud, sebagai pelengkap tiga komponen utama sistem anti fraud (preventive, detection, dan deterrence) yang digunakan selama ini demi memutus tindakan fraud dan menghadirkan rasa keadilan di tengah-tengah masyarakat.

Lebih lanjut, bagian kesimpulan ini mengambil judul "kesimpulan sementara" sebab artikel ini masih berupa analisa awal atas sistem anti fraud yang sesuai dengan konteks Indonesia. Selain itu, alasan dari penggunaan judul "kesimpulan sementara", lebih kepada agar dapat mendorong akademisi dan peneliti berikutnya untuk mengkaji pengembangan sistem anti fraud dengan menggunakan perspektif atau paradigma serta pendekatan metodologi yang berbeda sehingga akan semakin memperkaya khazanah pengetahuan tentang sistem anti fraud yang sesuai dengan konteks Indonesia yang hingga hari ini masih menjadi salah satu pekerjaan rumah besar bagi bangsa Indonesia.

\section{Daftar Rujukan}

ACFE. 2016. Report to The Nation on Occupational Fraud and Abuse. ACFE.

Amernic, J., dan R. Craig. 2009. "Understanding accounting through conceptual metaphor: Accounting is an instrument?". Critical Perspectives on Accounting, Vol. 20, No. 8, hlm: 875-883.

Bertot, J. C., P. T. Jaeger, dan J. M. Grimes. 2010. "Using ICTs to create a culture of transparency: E-government and social media as openness and anti-corruption tools for societies". Government Information Quarterly, Vol. 27, No. 3, hlm: 264-271.

Bierstaker, J. L. 2009. "Differences in attitudes about fraud and corruption across cultures: Theory, examples and recommendations". Cross Cultural Management: An International Journal, Vol. 16, No. 3, hlm: 241-250.

Bierstaker, J. L., R. G. Brody, dan C. Pacini. 2006. "Accountants' perceptions regarding fraud detection and prevention methods". Managerial Auditing Journal, Vol. 21, No. 5, hlm: 520-535.

Dorminey, J., A. S. Fleming, M.-J. Kranacher, dan R. A. Riley Jr. 2012. "The evolution of fraud theory". Issues in Accounting Education, Vol. 27, No. 2, hlm: 555-579.

Fairclough, N. 2013. Critical discourse analysis: The critical study of language: Routledge.

Google-Scholar. $2017 . \quad$ "budaya ronda" https://scholar.google.co.id/scholar?hl=en\&as_sdt=0\%2C5\&q=budaya + ronda\&btn $G=$. [diakses pada 3 November 2017].

Google. $2017.2 \quad$ "Budaya Ronda" https://www.google.co.id/search?dcr=0\&source=hp\&ei=ioMHWqjgGIuM8gWpyYzw Cw\&q=budaya + ronda\&oq=buday $a+$ ronda\&gs_l=psyab.3..35i39k1j0i22i30k112.2146.4624.0.4930.13.11.0.0.0.0.417.1583.0j1j4j0j1.6.0...0 ...1.1.64.psy-ab..7.6.1576.0..0j0i131k1j0i20i263k1.0.6NZby2B6zb8. [diakses pada 3 November 2017].

Haller, D., dan C. Shore. 2005. Corruption: anthropological perspectives: Pluto Press.

Historia.id. 2010. "Jangan Berpaling dari Siskamling" http://historia.id/budaya/janganberpaling-dari-siskamling. [diakses pada 2 November 2017]. 
Holtfreter, K., N. L. Piquero, dan A. R. Piquero. 2008. "And justice for all? Investigators' perceptions of punishment for fraud perpetrators". Crime, Law and Social Change, Vol. 49, No. 5, hlm: 397-412.

Hussien, M., dan T. Yamanaka. 2017. "Whistleblowing at work Can ICT encourage whistleblowing?". Joho Chishiki Gakkaishi, Vol. 27, No. 2, hlm: 150-154.

Indrayana, D. 2008. Negeri para mafioso: hukum di sarang koruptor: Penerbit Buku Kompas.

KBBI-DARING. 2017. "Ronda" https://kbbi.kemdikbud.go.id/entri/ronda. [diakses pada 3 November 2017].

Klikapa.com. 2016. "Kawanan Pencuri Gabah Bermobil Disergap Warga" http://www.klikapa.com/read/1924//14. [diakses pada 3 November 2017].

KPK. 2017. "Statistik Tindak Pidana Korupsi" https://acch.kpk.go.id/id/statistik/tindakpidana-korupsi. [diakses pada 3 November 2017].

Krjogja.com. 2016. "Pencuri Sarang Burung Nyaris Dihakimi Massa" http://krjogja.com/web/news/read/13469/home3.html. [diakses pada 3 November 2017].

Kusdewanti, A. I., A. R. Setiawan, A. Kamayanti, dan A. D. Mulawarman. 2014. "Akuntansi Bantengan: Perlawanan Akuntansi Indonesia Melalui Metafora Bantengan dan Topeng Malang". Jurnal Akuntansi Multiparadigma, Vol. 5, No. 1, hlm.

Lentera-Swara-Lampung. 2017. "Warga Srengsem Keroyorok Pencuri Rokok" http://lenteraswaralampung.com/berita-7311-warga-srengsem-keroyorok-pencurirokok.html [diakses pada 3 November 2017].

Lestari, A. D., I. Suntoro, dan Y. Nurmalisa. 2017. "PERANAN KEPALA KAMPUNG DALAM PELAKSANAAN SISKAMLING". Jurnal Kultur Demokrasi, Vol. 5, No. 1 , hlm.

Llewelyn, S. 2003. "What counts as "theory" in qualitative management and accounting research? Introducing five levels of theorizing". Accounting, Auditing \& Accountability Journal, Vol. 16, No. 4, hlm: 662-708.

Maftuchin, A. S., dan A. Budiyanto. 2017. "Tradisi Seni Patrol dan Identitas Budaya Kampung Bandulan di Kota Malang". Studi Budaya Nusantara, Vol. 1, No. 1, hlm.

Mahadewi, N. M. A. S. 2014. "Pecalang Simbol Kekuatan Budaya Bali". JURNAL ILMIAH SOSIOLOGI (SOROT), Vol. 1, No. 2, hlm.

Mantere, S., J. A. Sillince, dan V. Hämäläinen. 2007. "Music as a metaphor for organizational change". Journal of Organizational Change Management, Vol. 20, No. 3, hlm: 447-459.

Mulyana, D., dan J. Rakhmat. 1996. Komunikasi antarabudaya: panduan berkomunikasi dengan orang-orang berbada budaya. Bandung: Rosdakarya.

Nuryanto, H. 2012. Sejarah Perkembangan Teknologi Informasi dan Komunikasi: PT Balai Pustaka (Persero).

OKEZONE.COM. 2014. "Penanganan Korupsi Lamban, KPK Ngeluh Kekurangan Penyidik" https://news.okezone.com/read/2014/05/07/339/981144/penanganan-korupsi-lambankpk-ngeluh-kekurangan-penyidik. [diakses pada 4 november 2017].

. 2017. "Kriminalitas Marak di Bukittinggi, Polisi Imbau Warga Giatkan Ronda" https://news.okezone.com/read/2017/04/21/340/1673346/kriminalitas-marak-dibukittinggi-polisi-imbau-warga-giatkan-ronda. [diakses pada 3 November 2017].

Rafael, V. L. 1999. Figures of Criminality in Indonesia, the Philippines, and Colonial Vietnam: SEAP Publications.

Republika. 2017. "ICW: Pemberantasan Korupsi Lamban Sebab Diganggu Banyak Hal" http://nasional.republika.co.id/berita/nasional/hukum/17/07/01/oseyy5-icw- 
pemberantasan-korupsi-lamban-sebab-diganggu-banyak-hal. [diakses pada 4 November 2017].

Ritzer, G. 2010. Sociological Theory New York: McGraw-Hill.

Tribunnewsbogor.com. 2016. "Polisi Sebar Poster-poster Berisi Foto Teroris yang Jadi Buronan" http://bogor.tribunnews.com/2016/01/30/polisi-sebar-poster-poster-berisifoto-teroris-yang-jadi-buronan. [diakses pada 3 November 2017].

Wahyuni, A. S. 2015. "PREDATORY PRICING: PERSAINGAN HARGA MINIMARKET DAN GADDE-GADDE DALAM METAFORA CERPEN". Jurnal Akuntansi Multiparadigma, Vol. 6, No. 2, hlm: 237-244.

Whyte, D., dan J. Wiegratz. 2016. Neoliberalism and the Moral Economy of Fraud: Routledge.

Widodo, J. 2016. "Meneguhkan Identitas Budaya Nasional". Jurnal Bestari, Vol., No. 42, hlm.

Wolfe, D. T., dan D. R. Hermanson. 2004. "The fraud diamond: Considering the four elements of fraud". The CPA Journal, Vol. 74, No. 12, hlm: 38-42. 